\title{
Brucella Endocarditis Presenting With Findings Resembling Vasculitis
}

\author{
Fatih YILDIZ, ${ }^{1}$ Ertuğrul BAYRAM, ${ }^{2}$ Bayram KELLE, ${ }^{3}$ Eren ERKEN ${ }^{1}$ \\ ${ }^{1}$ Çukurova Üniversitesi Tip Fakültesi, Romatoloji-İmmünoloji Bilim Dall, Adana, Turkey \\ ${ }^{2}$ Çukurova Üniversitesi Tip Fakültesi, İç Hastalıkları Anabilim Dalı, Adana, Turkey \\ ${ }^{3}$ Çukurova Üniversitesi Tip Fakültesi, Fiziksel Tip ve Rehabilitasyon Anabilim Dal, Adana, Turkey
}

\begin{abstract}
Brucellosis is a zoonotic infection presenting with several systemic clinical symptoms. Cardiovascular involvement is observed in very rare of patients with brucellosis and the common involvement form is endocarditis. Heart failure is the prominent complication which may occur as a result of endocarditis. This type of infection may cause clinical symptoms including hematuria, proteinuria, and renal insufficiency. In this article, we report a patient with Brucella endocarditis resembling systemic vasculitis including hematuria, uremia, polyneuropathy, and epididymoorchitis findings.

Keywords: Brucellosis; endocarditis; nephritis; pulmonary edema; vasculitis.
\end{abstract}

Brucellosis is a zoonotic infection with a widely ranging global distribution and a high prevalence particularly in developing countries. It is frequently transmitted to humans via consumption of dairy products made from unpasteurized milk or direct contact with tissues of infected animals. Turkey is a country where brucellosis is endemic. ${ }^{1}$ The most common species is Brucella melitensis. Clinical manifestations of Brucella infection have a wide spectrum of musculoskeletal, genitourinary, gastrointestinal, hematologic, nervous, skin/mucosal, and respiratory system complications. ${ }^{2}$ Cardiac complications of brucellosis occur in less than $2 \%$ of patients and generally manifest in the form of endocarditis. Other possible manifestations include myocardial or pericardial involvement. Heart failure is a significant complication associated with endocarditis. Clinical pictures including heart failure, rhythm disturbances or acute pulmonary edema may occur as a result of cardiac involvement. ${ }^{3}$ In this article, we present a patient of Brucella endocarditis resulting in manifestations resembling systemic vasculitis.

\section{CASE REPORT}

A 48-year-old male patient admitted to our clinic with skin rash in arms and legs, dark urine color, and generalized joint pain. His history revealed that he had rheumatic heart disease and underwent a coronary angiography 10 months ago due to chest pain. Angiography had showed normal coronary arteries along with grade 2-3 aortic insufficiency and mild-to-moderate mitral stenosis. He was offered cardiac valve replacement. Physical examination showed a body temperature of $38.5{ }^{\circ} \mathrm{C}$, blood pressure of $120 / 80 \mathrm{mmHg}$, pulse of $99 \mathrm{bpm}$, and petechia in arms, legs and lower back region, and occasionally palpable purpura (Figure 1). The heart was rhythmic and grade 2-3/6 degree systolic murmur was present at apex and mitral focus. No rales or rhonchi were present in the lungs. Splenomegaly was detected during abdominal examination. Eye examination results were normal. Laboratory test results are shown in Table 1. Rheumatoid factor, antinuclear antibody, anti-double stranded DNA, anticardiolipin antibody, anti-neutrophil cytoplasmic antibodies,

Received: January 06, 2014 Accepted: October 22, 2014 Published online: February 21, 2015

Correspondence: Fatih Yıldız, M.D. Çukurova Üniversitesi Tıp Fakültesi, Romatoloji-Immünoloji Bilim Dalı, 01330 Sarıçam, Adana, Turkey.

Tel: +90 322 - 3386060 e-mail: drfatih75@gmail.com

O2015 Turkish League Against Rheumatism. All rights reserved. 
Table 1. Laboratory tests of the patient

\begin{tabular}{|c|c|c|}
\hline Parameters & Results & Normal range \\
\hline Leukocyte count $\left(\mathrm{mm}^{3}\right)$ & 11.900 & 4.3-10.3 \\
\hline $\mathrm{Hb}(\mathrm{gr} / \mathrm{dL})$ & 8.3 & $13.6-17.2$ \\
\hline $\mathrm{MCV}(\mathrm{fL})$ & 75 & $80.7-95.5$ \\
\hline Platelet $\left(\mathrm{mm}^{3}\right)$ & 143.000 & $156-373$ \\
\hline ESR (mm/hour) & 36 & $0-25$ \\
\hline Total protein (gr/dL) & 5.6 & $6.6-8.7$ \\
\hline Albumin $(\mathrm{gr} / \mathrm{dL})$ & 2.7 & $3.4-4.8$ \\
\hline AST (IU/L) & 22 & $<31$ \\
\hline ALT (IU/L) & 18 & $<31$ \\
\hline BUN (mg/dL) & 63 & $5-20$ \\
\hline Creatinine (mg/dL) & 3.4 & $0.8-1.2$ \\
\hline $\mathrm{CRP}(\mathrm{mg} / \mathrm{L})$ & 87 & $0-8$ \\
\hline PTT (sec) & 14.5 & $10.5-13.2$ \\
\hline INR & 1.26 & $0.85-1.2$ \\
\hline $\operatorname{IgA}(\mathrm{mg} / \mathrm{dL})$ & 316 & $45-380$ \\
\hline $\mathrm{C} 3(\mathrm{~g} / \mathrm{L})$ & 0.49 & $0.89-1.87$ \\
\hline $\mathrm{C} 4(\mathrm{~g} / \mathrm{L})$ & 0.114 & $0.165-0.380$ \\
\hline Iron $(\mu \mathrm{g} / \mathrm{dL})$ & 50 & $75-175$ \\
\hline Iron-binding capacity $(\mu \mathrm{g} / \mathrm{dL})$ & 273 & $300-400$ \\
\hline Ferritin $(\mathrm{ng} / \mathrm{mL})$ & 350 & $20-300$ \\
\hline \multicolumn{3}{|c|}{$\begin{array}{l}\text { Hb: Hemoglobin; MCV: Mean Corpuscular Volume; ESR: Erythrocyt } \\
\text { sedimentation rate; AST: Aspartate transaminase; ALT: Alanin } \\
\text { aminotransferase; BUN: Blood urea nitrogen; CRP: C-reaktive protein } \\
\text { PTT: Partial thromboplastin time; INR: International normalized ratio; IgA } \\
\text { Immunoglobulin A; C3: Complement 3; C4: Complement } 4 \text {. }\end{array}$} \\
\hline
\end{tabular}

hepatitis B-C, human immunodeficiency virus, and Salmonella tests were negative. Complete urinalysis showed abundant red blood cells and leukocyte clusters, and 1+ proteinuria. Esbach's test for 24-hour urine was negative.

Systemic vasculitic conditions, mainly polyarteritis nodosa were investigated in the patient. Weight loss and epididymo-orchitis were observed. Electromyography findings were consistent with motor polyneuropathy. The source of fever was investigated and blood and urine cultures were obtained. Ceftriaxone

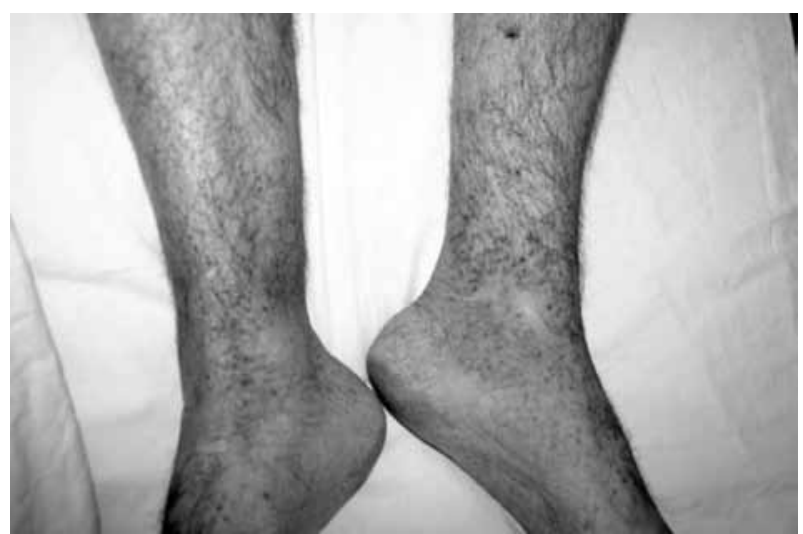

Figure 1. Petechia and purpura in both legs, more evident in both medial malleolus. intravenous was started at a daily dose of $2 \mathrm{~g}$. Electrocardiography showed left atrial anomaly and transthoracic echocardiography findings included $68 \%$ of ejection fraction, left ventricular cavity dilation, aortic valve calcification, mild mitral stenosis, advanced mitral insufficiency, and severe aortic insufficiency. Abdominal ultrasonography showed splenomegaly and normal kidney size. Ultrasound impression revealed grade 2-3 bilateral renal parenchymal disease. Lower extremity, renal, and portosplenic color Doppler ultrasound results were normal. Skin biopsy was non-contributory. Muscle biopsy to assess vasculitic neuropathy did not help diagnosis. Brucella tube dilution was positive at 1/160 titration (IU/L). Blood culture showed growth of Brucella melitensis. Transesophageal echocardiography (TEE) was performed for endocarditis. Vegetation was detected in the aortic valve. Ultimately, diagnosis was confirmed as infective endocarditis due to Brucella infection. Antibiotic therapy was switched to ciprofloxacin, doxycycline, and rifampicin.

During the follow-up, the patient developed shortness of breath, orthopnea and paroxysmal nocturnal dyspnea. He was referred to the intensive care unit and followed for acute pulmonary edema (Figure 2). Nitroglycerine and furosemide infusions were started and his clinical symptoms improved. Laboratory work-up for anemia etiology revealed $1+$ direct Coombs' test, low iron level and iron-binding capacity

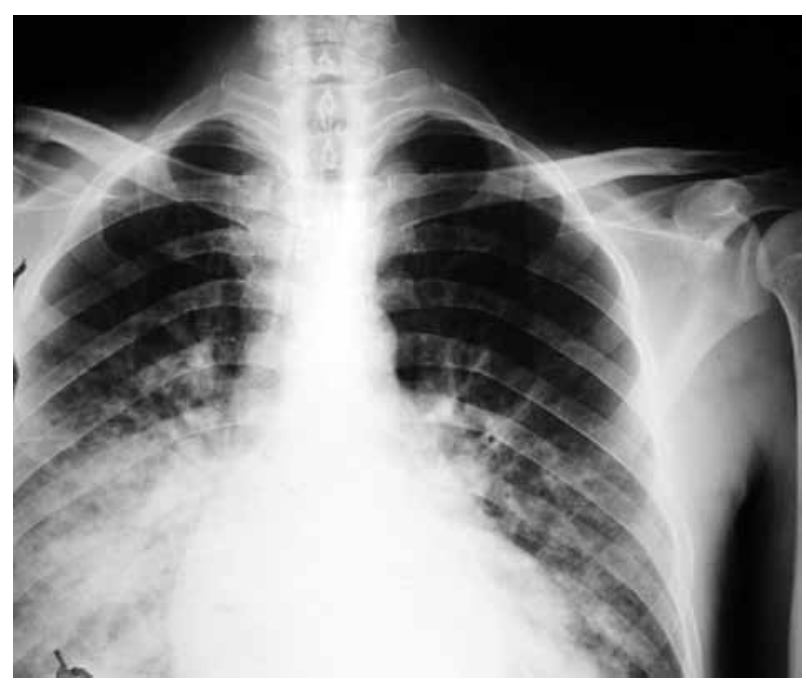

Figure 2. Posteroanterior chest X-ray showing pulmonary edema. 


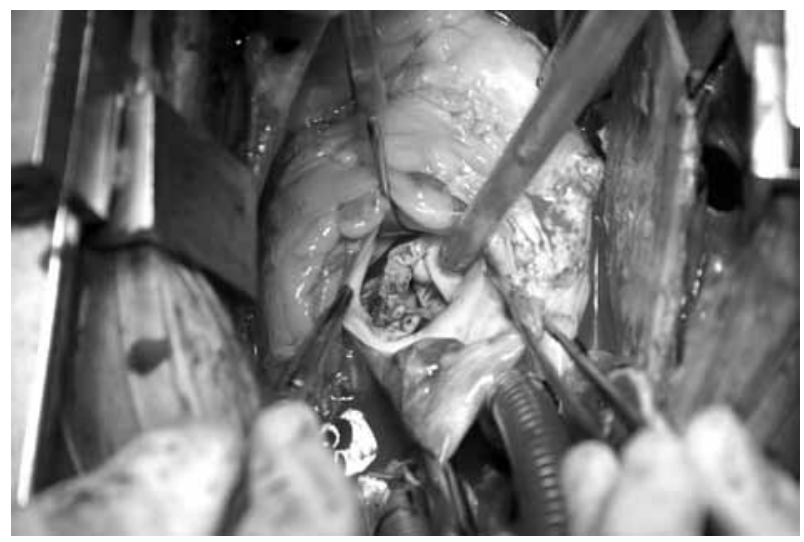

Figure 3. Intraoperative imaging demonstrating aortic valve vegetation.

and a high ferritin level (Table 1). Analysis of peripheral blood smear showed no signs of hemolysis. Patient's findings were consistent with anemia of chronic illness. One unit of red blood cell transfusion was performed to increase hemoglobin level to $10 \mathrm{~g} / \mathrm{dL}$. A follow-up TEE was performed two weeks later to assess response to treatment. Vegetations were still present in aortic non-coronary $(15 \times 6 \mathrm{~mm})$ and coronary $(3 \times 4 \mathrm{~mm})$ valves. Surgical operation was preferred after consultation with Cardiovascular Surgery and Cardiology Departments. During the operation, aortic valve with vegetation was resected and replaced with a prosthetic valve (Figure 3 ). Additionally, mitral valve showing advanced insufficiency was resected and replaced with a prosthetic mitral valve. During the follow-up, the patient was heparinized and warfarin was initiated. Creatinine levels followed a stable level at about $2.5 \mathrm{mg} / \mathrm{dL}$. He did not have fever during follow-up and his treatment for infective endocarditis was completed in six weeks. Renal biopsy was offered but the patient did not consent.

\section{DISCUSSION}

Brucella is diagnosed based on clinical signs and symptoms, including Brucella tube agglutination titration equal to or greater than 1/160 and/or growth of Brucella species in blood, bone marrow or other tissue cultures. ${ }^{4}$

Cutaneous symptoms of brucellosis occur in $5-10 \%$ of patients. Exogenous forms include contact dermatitis or primary abscess. Endogenous forms have been described as erythema nodosum, papules, petechia, purpura, vesicular lesions, psoriasiform and eczema lesions, urticaria-like lesions and impetiginous rashes. ${ }^{5}$ Urogenital involvement is seen in $2-10 \%$ of brucellosis patients and clinically presents with unilateral epididymo-orchitis in male patients. ${ }^{6}$ Our patient had epididymo-orchitis unilaterally on the right side. This condition was consistent with the literature.

Cardiac complications of brucellosis are not common. Less than $2 \%$ of patients with brucellosis shows cardiovascular involvement and the most common form is endocarditis., ${ }^{2,-9}$ Myocarditis and heart failure develop rarely. ${ }^{10}$ Brucella pericarditis without endocarditis was reported in a limited number of patients. ${ }^{11}$ Although the risk of developing endocarditis in brucellosis is low, deaths from brucellosis are majorly caused by endocarditis and associated development of congestive heart failure. Usually aortic valve is affected, requiring urgent surgical valve replacement. ${ }^{12}$ Heart failure, rhythm disorders or acute pulmonary edema may occur in patients as a result of cardiac involvement. Aortic valve endocarditis may lead to acute myocardial infarction. The mechanism for cardiac damage is unclear but it may be related directly to the culprit microorganism or develop as a result of accumulating local immune complexes. ${ }^{13}$

Transesophageal echocardiography is required for patients who are suspected of having endocarditis due to new-onset cardiac murmur, valvular involvement, and unexplained fever. As in our patient, vegetations may not be apparent during TEE. Large vegetations in affected heart valves, ulceration and abscesses in myocardium, microabscesses in valves, and destruction and calcifications of perivalvular areas and valves may be observed during TEE. ${ }^{14}$ These lesions may cause emboli.

Patients of glomerulonephritis and renal vasculitis have been reported in association with Brucella endocarditis. ${ }^{15}$ This infection was reported to be possibly associated with hematuria, proteinuria, and renal failure in areas where brucellosis is endemic. Renal involvement including tubulointerstitial nephritis and membranoproliferative nephritis was reported in brucellosis with or without endocarditis. 
Brucella species may invade kidney glomeruli, interstitium or renal vessels. Membranous glomerulopathy, immunoglobulin A nephropathy, mesengiocapillary glomerulonephritis, diffuse or focal proliferative mesengial glomerulonephritis, interstitial nephritis, renal and perinephric abscesses, and caseating granuloma have been reported. ${ }^{16}$ Direct bacterial invasion, hypersensitivity reactions mediated by immune complex and direct cytokine-related injury have been suggested as pathogenic mechanisms for Brucella nephritis. ${ }^{5}$ In our patient, renal failure might have resulted from immune complex glomerulonephritis associated with endocarditis or caused directly from Brucella infection. However, we were unable to reach a definitive conclusion in the absence of renal biopsy.

Endocarditis is an unlikely but lifethreatening complication of brucellosis. In general, a combination of surgery and medical therapy should be preferred for the treatment of endocarditis associated with brucellosis. ${ }^{17}$ Conservative treatment with antibiotics was suggested as an adequate therapeutic approach, particularly in the patient subset without heart failure. Aminoglycoside combination is the most commonly preferred drug combination. Doxycycline plus rifampicin $(77 \%)$ is the most widely used combination followed by doxycycline and rifampicin combined with streptomycin or gentamicin (9\%). ${ }^{4}$ Optimal duration of therapy is not clear but treatment may be given at least for six weeks and extended up to three months. ${ }^{18}$ Quinolone was preferred in our patient since aminoglycosides are known to be nephrotoxic.

In conclusion, Brucella endocarditis may lead to a clinical picture resembling systemic vasculitis with cutaneous symptoms, hematuria, uremia, polyneuropathy, and epididymo-orchitis. Therefore, Brucella infection should be kept in mind when investigating systemic vasculitis, particularly in endemic areas.

\section{Declaration of conflicting interests}

The authors declared no conflicts of interest with respect to the authorship and/or publication of this article.

\section{Funding}

The authors received no financial support for the research and/or authorship of this article.

\section{REFERENCES}

1. Efe C, Can T, Ince M, Tunca H, Yildiz F, Sennaroglu E. A rare complication of Brucella infection: myocarditis and heart failure. Intern Med 2009;48:1773-4.

2. Kursun E, Turunc T, Demiroglu Y, Arslan H. Evaluation of four hundred and forty seven brucellosis cases. Intern Med 2013;52:745-50.

3. Colmenero JD, Reguera JM, Martos F, Sánchez-De-Mora $\mathrm{D}$, Delgado M, Causse M, et al. Complications associated with Brucella melitensis infection: a study of 530 cases. Medicine (Baltimore) 1996;75:195-211.

4. Kurtaran B, Candevir A, Inal AS, Komur S, Akyildiz $\mathrm{O}$, Saltoglu N, et al. Clinical appearance of brucellosis in adults: fourteen years of experience. Turk J Med Sci 2012;42:497-505.

5. Shoja MM, Khosroshahi HT, Tubbs RS, Varshochi M, Fervenza FC. Brucellosis mimicking vasculitis in a patient with renal failure and peripheral neuropathy. Am J Med Sci 2008;36:285-87.

6. Doğanay M, Meşe Alp E. Bruselloz. In: Topçu AW, Söyletir G, Doğanay M, editörler. Enfeksiyon Hastalıkları ve Mikrobiyolojisi. 3rd ed. İstanbul: Nobel Tip Kitabevleri; 2008. s. 897-909.

7. Buzgan T, Karahocagil MK, Irmak H, Baran AI, Karsen H, Evirgen $\mathrm{O}$, et al. Clinical manifestations and complications in 1028 cases of brucellosis: a retrospective evaluation and review of the literature. Int $J$ Infect Dis 2010;14:469-78.

8. Akdeniz H, Irmak H, Demiröz AP. Evaluation of brucellosis cases in Van region of Eastern Anatolia: a-3 year experience. Nagoya Med J 1998;42:101-10.

9. Kokoglu OF, Hosoglu S, Geyik MF, Ayaz C, Akalin S, Buyukbese MA, et al. Clinical and laboratory features of brucellosis in two university hospitals in Southeast Turkey. Trop Doct 2006;36:49-51.

10. García de Lucas MD, Castillo Domínguez JC, Martínez González MS. Brucella myopericarditis. Rev Esp Cardiol 2004;57:709.

11. Kaya S, Eskazan AE, Elaldi N. Brucellar pericarditis: a report of four cases and review of the literature. Int $\mathrm{J}$ Infect Dis 2013;17:428-32.

12. Mantur BG, Amarnath SK, Shinde RS. Review of clinical and laboratory features of human brucellosis. Indian J Med Microbiol 2007;25:188-202.

13. Ugartemendía MC, Curós-Abadal A, Pujol-Rakosnik M, Pujadas-Capmany R, Escrivá-Montserrat E, Jané-Pesquer J. Brucella melitensis pericarditis. Am Heart J 1985;109:1108.

14. Mert A, Kocak F, Ozaras R, Tabak F, Bilir M, Kucukuglu S, et al. The role of antibiotic treatment alone for the management of Brucella endocarditis in adults: a case report and literature review. Ann Thorac Cardiovasc Surg 2002;8:381-85.

15. Elzouki AY, Akthar M, Mirza K. Brucella endocarditis associated with glomerulonephritis and renal vasculitis. Pediatr Nephrol 1996;10:748-51.

16. Altiparmak MR, Pamuk GE, Pamuk ON, Tabak F. Brucella glomerulonephritis:review of the literature and report on the first patient with brucellosis and mesangiocapillary glomerulonephritis. Scand J Infect Dis 2002;34:477-80.

17. WHO/CDS/EPR/2006.7. Brucellosis in humans and animals. Geneva: World Health Organization; 2006.

18. Koruk ST, Erdem H, Koruk I, Erbay A, Tezer-Tekce Y, Erbay AR, et al. Management of Brucella endocarditis: results of the Gulhane study. Int $\mathrm{J}$ Antimicrob Agents 2012;40:145-50. 